\title{
Experimental assessment of alluviation downstream of Hun-lock, Belgium
}

\author{
Catherine Swartenbroekx ${ }^{1}$, Céline Savary ${ }^{1}$, and Didier Bousmar ${ }^{1}$ \\ ${ }^{1}$ Hydraulic Research Laboratory, Service public de Wallonie, 6200 Châtelet, Belgium \\ Corresponding author: catherine.swartenbroekx@spw.wallonie.be
}

\begin{abstract}
To maintain inland navigation, a deposition crest in the Hunlock area, in the Upper Meuse River, Belgium, has to be dredged almost every two years. A long-term solution is searched for, based on the understanding of water velocity field and solid transport processes, to avoid the silting and the expensive dredging. The physical process is analysed thanks to a 1:50 small-scale model of the $500 \mathrm{~m}$-long Meuse reach with Hun movable dam as upstream boundary. The velocity fields, recorded with an electromagnetic probe displaced automatically, are compared for several configurations. Three discharges and distinct dam openings are tested in the existing configuration. Modifications of the downstream guard wall, by perforating ports, are also considered. Building groynes in the right side of the river is analysed. Finally, flushing water through the lock is tested. As conclusions, alluviations are due to the localisation of the lock in an enlarged area of the Upper Meuse and in a meander intrados, inducing decreasing flow velocities. None of the tested solutions is completely convincing according to 4 criterions: (1) ability to decrease the deposition crest, (2) navigation requirements, (3) safety in case of high-stage discharges, and (4) acceptable cost.
\end{abstract}

\section{Introduction}

To ensure a safe and efficient inland navigation, the water depth has to be sufficient in the waterways. For instance, the vessel draught ranges between $2.5 \mathrm{~m}$ and $4.5 \mathrm{~m}$ for ECMT class IV (1350 t) and Va (2000 t), respectively. Alluviations should then be removed regularly from shipping channels and rivers to maintain the navigation. However, the excavation process and the dredged material treatment are expensive. A better understanding of sediment transport and siltation processes may diminish the frequency of recurrent dredging.

This paper is devoted to the deposition crest in the Hun-lock area, which has to be dredged almost every two years. A long-term solution is searched for, based on the understanding of water velocity field and solid transport processes, to avoid the expensive dredging. The new design should respect four criterions: (1) ability to decrease the deposition crest, (2) navigation requirements, (3) safety in case of high-stage discharges, and (4) acceptable cost.

Hun movable dam is located on the Upper Meuse River, in the south of the city of Namur in Belgium, and is made of four $22.5 \mathrm{~m}$-wide sluices (denoted P1 to P4, from right 
to left bank, in Fig. 1). Each opening is closed by a radial gate on top of which is sat an upper flap gate. A movable hydropower station is installed in the right sluice (P1). It is designed in the following way: at low discharge, the gate is opened in such a way that the main discharge flows through the turbine; when the discharge increases (above $500 \mathrm{~m}^{3} / \mathrm{s}$ ), the hydropower unit is lifted out of the flow to let the gate recover the control (up to $1800 \mathrm{~m}^{3} / \mathrm{s}$ ). The lock, located on the left of the dam, belongs to ECMT class IV (1350 t, $100 \mathrm{~m} \times 12 \mathrm{~m})$. More details are given by [1].

The bathymetry collected in the field in 2015 (Fig. 1) shows the deposition crest forming at the lower lock approach (red and yellow area) with a maximum level $z_{b, \max , p}=$ $82.6 \mathrm{~m}$ above the sea level. An erosion area is observed downstream of the mobile weir apron $\left(z_{b, \min , p}=79.1 \mathrm{~m}\right)$. No information is available about the granulometry.

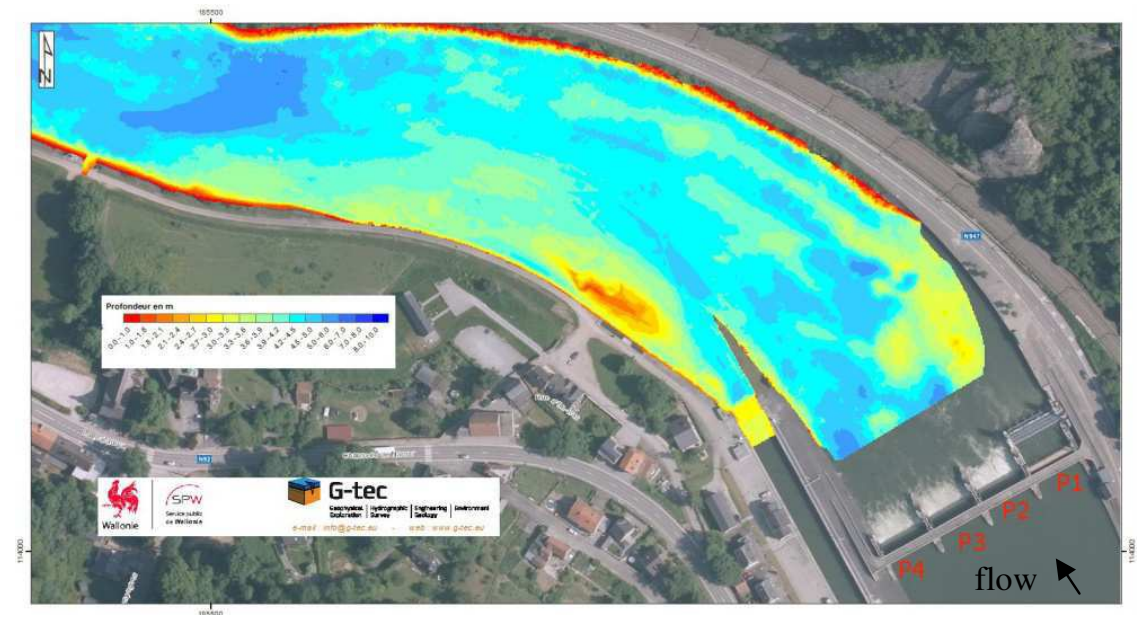

Fig. 1. Bathymetry in Hun in 2015 [2]). Red : deposition ; blue : erosion.

\section{Experimental set-up}

The flow velocity field is analysed downstream the Hun-lock thanks to a scale model, built in the Hydraulic Research Laboratory of the Walloon administration. Due to space and discharge constraints, the chosen scale is 1:50 according to Froude similarities [3]. By notation, the index $p$ is related to prototype or field data while the index $m$ corresponds to physical model values. The $x$-, $y$-, and $z$-axis are the streamwise, the transverse and the upward vertical axis, respectively.

\subsection{Flume characteristics}

The flume is $L_{m}=16 \mathrm{~m}$ long and $l_{m}=6 \mathrm{~m}$ wide. The downstream part of the model stands for an about $L_{p} \approx 500 \mathrm{~m}$-long reach of the Upper Meuse River, including the downstream part of the bend showed in Fig. 1, with Hun mobile weir as upstream boundary (Fig. 2). The fixed bed was scaled according to the bathymetry measured in the field in 2015 , with the deposition crest limited to the level $z_{b, p}=80.7 \mathrm{~m}$.

The water supply is realised by the laboratory's water recirculation pipe system. An upstream tank and an inlet section allow for a homogeneous inlet flow. The tailwater level can be regulated via a flap gate at the end of the flume. The incoming discharge $Q_{m}$ can vary between $51 / \mathrm{s}$ and $250 \mathrm{l} / \mathrm{s}$. 


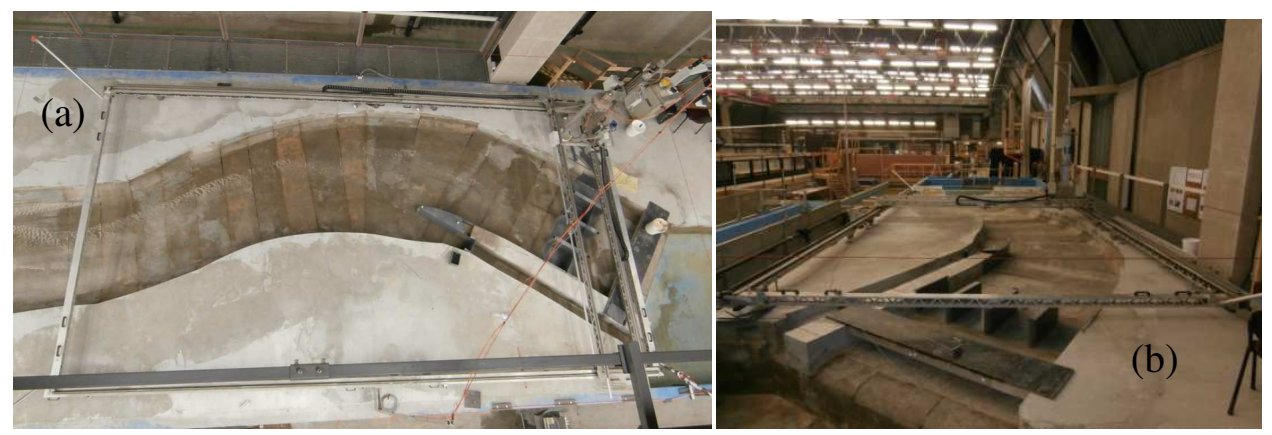

Fig. 2. Physical model and trolley: (a) plan view, (b) upstream view.

\subsection{Configurations}

Several field discharges $Q_{p}$ (from 250 to $1000 \mathrm{~m}^{3} / \mathrm{s}$ ) are compared. A discharge $Q_{p}=$ $250 \mathrm{~m}^{3} / \mathrm{s}\left(Q_{m}=14.1 \mathrm{l} / \mathrm{s}\right)$ occurs about 100 days a year while a discharge $Q_{p}=500 \mathrm{~m}^{3} / \mathrm{s}\left(Q_{m}\right.$ $=28.2 \mathrm{l} / \mathrm{s}$ ), for which the hydropower unit is lifted, occurs about 15 days a year. The usual downstream free surface level is then $z_{w, p}=84.36 \mathrm{~m}$ above the sea level and the water depth $h_{w, p}$ ranges between $1.76 \mathrm{~m}$ and $5.26 \mathrm{~m}$ depending on the bed level $\left(h_{w, m} \approx 3-10 \mathrm{~cm}\right)$. The usual upstream free surface level is $z_{w, p}=87.16 \mathrm{~m}$. During a high stage discharge $Q_{p}=$ $1000 \mathrm{~m}^{3} / \mathrm{s}\left(Q_{m}=56.61 / \mathrm{s}\right)$, the navigation is prohibited in the flow direction.

It was checked that the flow is almost homothetic: the velocity magnitudes are proportional to the discharges for a same imposed water level. However, the relative electromagnetic probe accuracy increases with the discharge. Besides, it is expected that the sediment concentration increases with the discharge. There is usually more solid transport at higher discharges. These two reasons justify using high discharges in the present analysis.

Distinct dam openings (flow through the whole dam, through two sluices or through the hydropower plant only) are tested in the present configuration. Perforating the downstream guard wall and building groynes in the right side of the river is also considered. Finally, flushing water through the lock toward the alluviations is tested.

\subsection{Measurement equipment}

The discharge is measured by means of electromagnetic flow meters installed in the supply line, with an accuracy of $0.2 \%$. The water level is measured in seven fixed locations with ultrasonic gauges. The water depth $h_{w, m}$ ranges between 3 and $10 \mathrm{~cm}$. The sensor accuracy is claimed to equal $0.3 \mathrm{~mm}$.

The velocity components are recorded in a grid of points with an electromagnetic probe Deltares PEMS-30, which is located on a trolley and displaced automatically at a mid-depth $h_{m}=4 \mathrm{~cm}\left(h_{p}=2 \mathrm{~m}\right)$. The small water depth does not allowed several measurements in the vertical profile. An automatic trolley (Fig. 2) enables to follow the same grid of measurement points during each test. The cross-sections are separated by $\Delta x_{m l}=10 \mathrm{~cm}$ near the lower guard wall and $\Delta x_{m 2}=50 \mathrm{~cm}$ elsewhere. The measurements are recorded during $30 \mathrm{~s}$ at $20 \mathrm{~Hz}$ every $\Delta y_{m, l}=10 \mathrm{~cm}$ in the cross-sections. The electromagnetic probe accuracy is about $\Delta v_{m}=1 \mathrm{~cm} / \mathrm{s}$.

The data acquisition is handled by means of the software HydroCap 3, a in-house environment developed with Labview [4]. 


\section{Results and discussion}

\subsection{Existing configuration and run reproducibility}

The velocity field measured in the existing configuration when the discharge $Q_{p}=500 \mathrm{~m}^{3} / \mathrm{s}$ and with the dam fully-open is displayed in Fig. 3 (blue vectors). It is superimposed to the bathymetry limit (in red). A black line in the lower left corner stands for a vector magnitude of $1 \mathrm{~m} / \mathrm{s}$. The maximum velocity, converted in prototype scale, is $v_{p}=1.37 \mathrm{~m} / \mathrm{s}$.

A dead water area is noticed downstream the lock. The small velocities are due to 2 phenomena: (1) the lock is located in a significant enlarged area of the Upper Meuse in comparison with the mean width and (2) the lock channel is built in a meander intrados. The flow crossing the dam is then mainly directed towards the meander extrados, i.e. the right side of the Upper Meuse, while the downstream lock channel in the left side is hidden by the river inflexion point and by the guard wall. Moreover, recirculation zones and vortices are generated between both areas, by reflexion or shearing processes. Because of the slow flow behind the lock and the vortices, siltation is occurring.

Two runs operated in similar conditions are satisfactorily compared (Fig. 3 a-b).
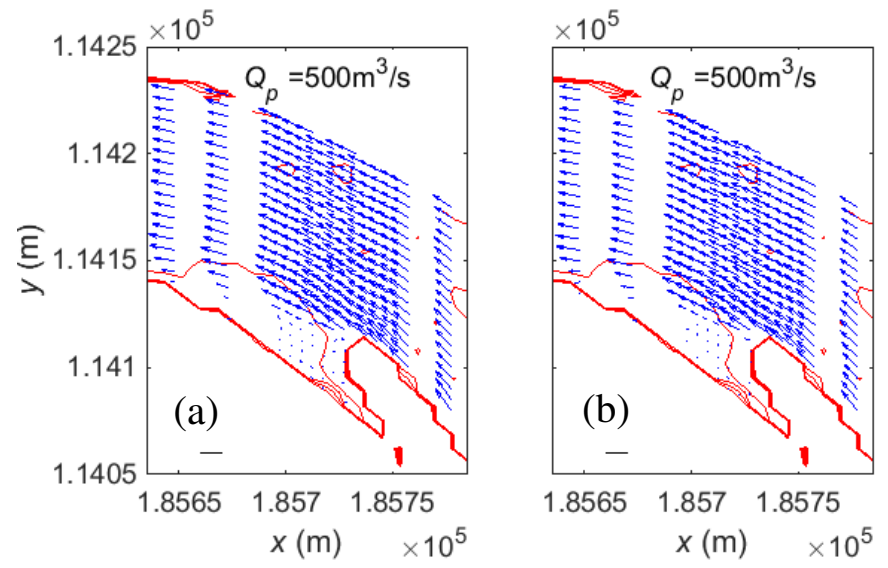

Fig. 3. Velocity field $v_{p}$ when $Q_{p}=500 \mathrm{~m}^{3} / \mathrm{s}$ with 4 open sluices: (a) run 1 , (b) run 2 .

\subsection{Impact of the sluice opening}

In Fig. 4, distinct dam openings are tested in the present configuration when $Q_{p}=250 \mathrm{~m}^{3} / \mathrm{s}$ : (a) through the hydropower plant only (= P1) and (b) flow through the left sluice P4 only. Two tendencies are seen depending on which side the discharge is flowing through the dam: (a) a global anticlockwise recirculation area in the whole downstream river width and (b) a clockwise recirculation area downstream the dam and a small anticlockwise vortex in the lock channel. These flows do not impede alluviations. 

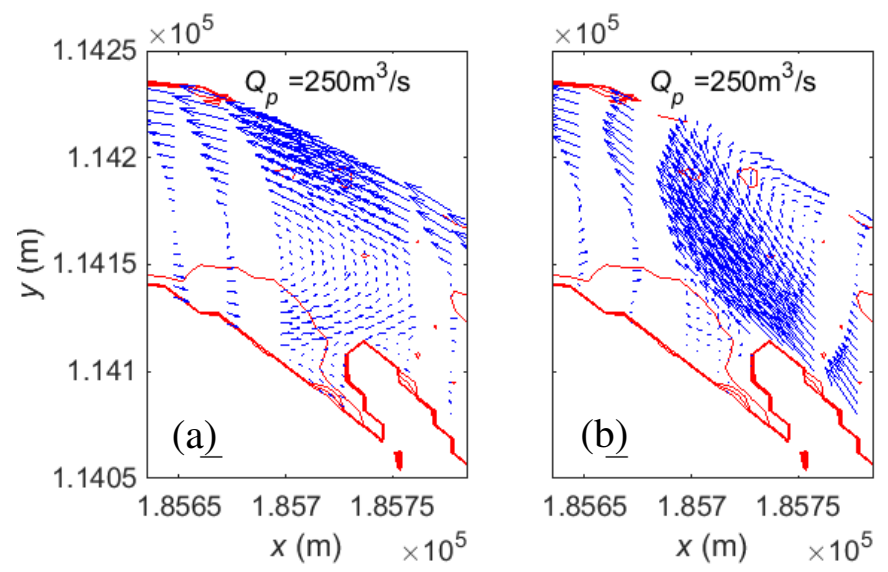

Fig. 4. Velocity field $v_{p}$ when $Q_{p}=250 \mathrm{~m}^{3} / \mathrm{s}$ with 1 open sluice: (a) P1 open, (b) P4 open.

\subsection{Perforated guard wall}

The lower guard wall separates the downstream harbour entrance from the dam channel, to protect the vessels from currents when they are manoeuvring to enter or leave the lock [5]. In the existing configuration, it is a solid wall. Five openings are perforated in the scale model (Fig. 5), to let the water from the weir channel flowing toward the lock channel. These ports angle $55^{\circ}$ with the wall axis. Similar designs were seen in other studies to reduce recirculation downstream the lock $[6,7]$.

For a discharge $Q_{p}=500 \mathrm{~m}^{3} / \mathrm{s}$, if sluices $\mathrm{P} 1$ and $\mathrm{P} 2$ are open, the global anticlockwise recirculation remains and is amplified (Fig. 6a). The water flows through the ports in the upstream direction. This layout is worse than the existing one regarding the siltation risk. If sluices P1 and P4 are open, there is still a vortex at the harbour entrance (Fig. 6b). Again, the local enlargement of River Meuse is too sharp. This causes the diverging flow to detach from its side border.

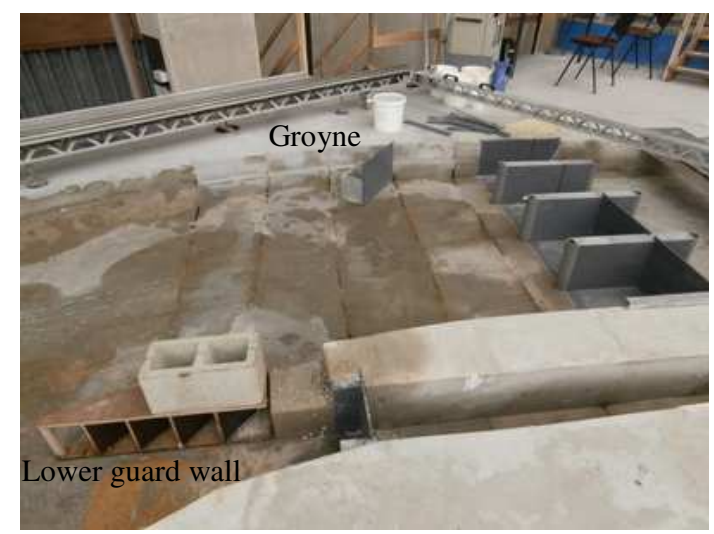

Fig. 5. Perforated guard wall and groyne in the right side. 

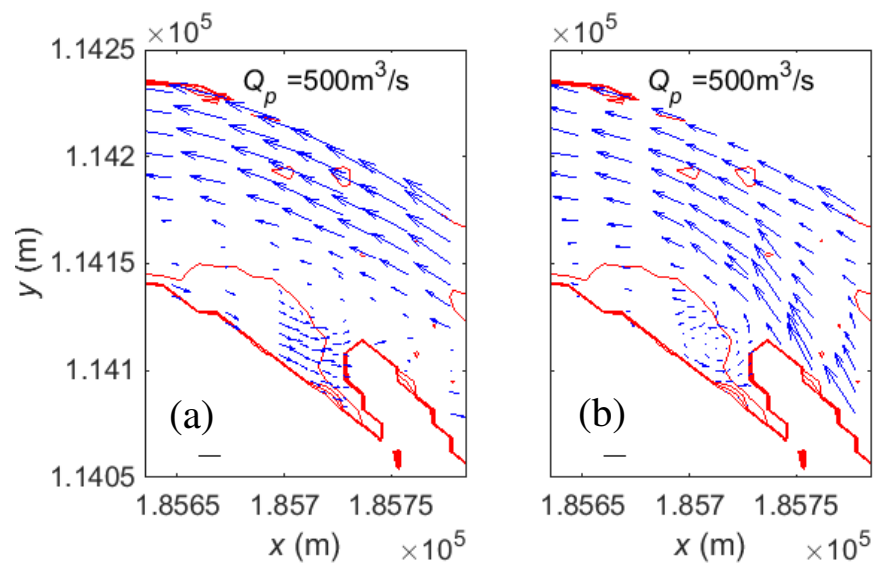

Fig. 6. Velocity field $v_{p}$ when $Q_{p}=500 \mathrm{~m}^{3} / \mathrm{s}$ with a perforated guard wall with (a) $\mathrm{P} 1$ and $\mathrm{P} 2$ open and (b) P1 and P4 open.

\subsection{Groynes}

Considering that the flow will probably detach from one of its sides in any case, a groyne is added in the right side of the river, to direct the flow toward the perforated guard wall (Fig. 5). This solution is not realistic because it increases the flood risk, by obstructing the flow from the hydropower plant during high stage periods. However, if diminishing the alluviation convincingly, the groyne design could be adapted to face the flood risk.

The velocity fields depicted in Fig. 7 shows that the combine presence of a perforated guard wall and a groyne allows the flow to be directed toward the existing deposition crest if and only if sluices P1 and P2 are open (Fig. 7a). A recirculation zone is then appearing in the right side, downstream the groyne, where there is no navigation.
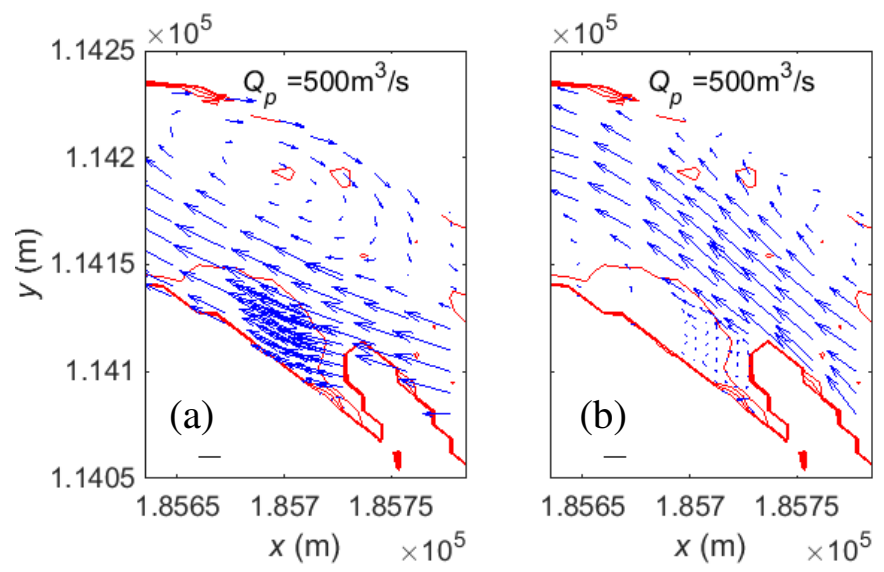

Fig. 7. Velocity field $v_{p}$, when $Q_{p}=500 \mathrm{~m}^{3} / \mathrm{s}$ with a perforated guard wall and with groyne: (a) with P1 and P2 open, (b) with P1 and P4 open.

The above paragraph shows that a groyne, which obstructs the whole depth, is useful to diminish the alluviation if sluices $\mathrm{P} 1$ and $\mathrm{P} 2$ are open. To avoid flood risk, two half-depth groynes orientated towards the perforated guard wall are tested (Fig. 8a). However, the global anticlockwise recirculation is then acting again (Fig. 8b). 

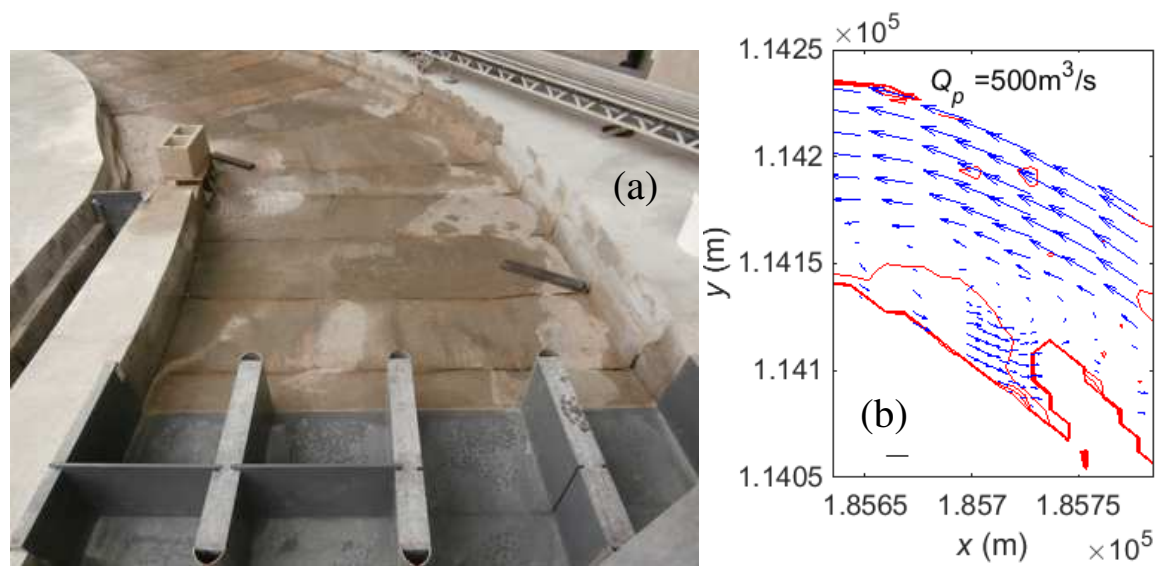

Fig. 8. Perforated wall and 2 half-depth groynes with P1 and P2 open: (a) upstream view. (b) velocity field $v_{p}$ when $Q_{p}=500 \mathrm{~m}^{3} / \mathrm{s}$.

\subsection{Flushing water through the lock}

Finally, in a first attempt to flush water through the lock toward the alluviation area, a discharge $Q_{p}=500 \mathrm{~m}^{3} / \mathrm{s}$ is directed through two sluices and the lock, in the existing configuration (with the solid guard wall). The discharge through the lock exceeds $100 \mathrm{~m}^{3} / \mathrm{s}$, which is higher than what is available through the lock filling system (the available discharge is expected to reach about $40 \mathrm{~m}^{3} / \mathrm{s}$ if opening simultaneously both upstream and downstream valves).

The velocity field (Fig. 9) shows that the water volume coming from the lock covers the alluviation area partially. It should thus carry a part of the sediments. The alluviation area is more eroded if the sluice P4 (along the guard wall) is open because the flow is then more directed toward the left side (Fig. 9b). Nevertheless, whatever the open sluice, an alluviation area remains unaffected by the flushing water, even with an overvalued discharge. The deposition area will not completely disappear.
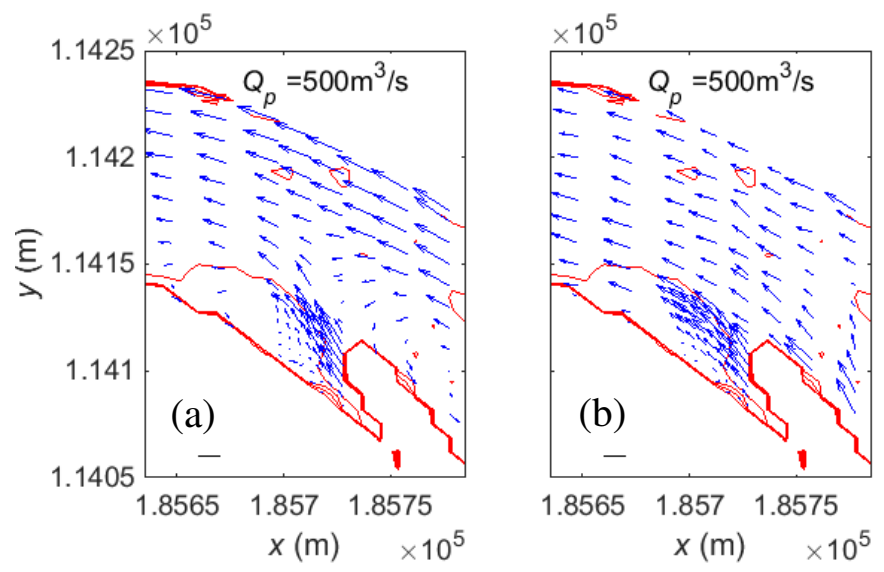

Fig. 9. Velocity field $v_{p}$ during flushing water through the lock when $Q_{p}=500 \mathrm{~m}^{3} / \mathrm{s}$ : (a) $\mathrm{P} 1$ and $\mathrm{P} 2$ open, (b) P1 and P4 open. 


\section{Conclusions}

The paper described a case study of sediment deposition in the Hun-lock area in the Upper Meuse River. Attempts to mitigate the siltation are compared thanks to a physical model.

The velocity field analysis explains the alluviation processes qualitatively. They are due to the localisation of the lock in an enlarged area of the Upper Meuse and in a meander intrados, where the flow velocity is decreasing. Distinct recirculation zones and vortices are highlighted, depending on the dam opening, the guard wall design, the presence of groynes and the lock use. Further investigations through a shear stress analysis could detail the impact of these velocity fields on sediment transport.

Finally, the comparison shows that none of the tested solutions is completely convincing according to 4 criterions: (1) ability to decrease the deposition crest, (2) navigation requirements, (3) safety in case of high-stage discharges, and (4) acceptable cost.

The proposal to transform the existing solid guard wall into a perforated wall and, simultaneously, to build a groyne downstream the hydropower plant is efficient to impede the recirculation areas. Nevertheless, this solution is expensive and increases the flood risk during high-stage periods.

To diminish the dredge frequency, flushing water through the lock is efficient partially. However, the discharge that could be released from the lock filling system is limited. Recurrent dredging will still be needed, as remaining the cheapest and only efficient solution.

The authors acknowledge the contribution of the technical staff of the Hydraulic Research Laboratory as well as the master students who participated in the model building and measurements.

\section{References}

1. C. Swartenbroekx, Y. Libert, Barrage de Hun - Modélisation physique des atterrissements à l'aval de l'écluse de Hun. Rapport final. Service public de Wallonie, Belgium (in French) (2017)

2. G-tec-SPW, HydroWalMap website, https://www.hydrowalmap.be/app/ consulted on February (2017)

3. H. Kobus, Hydraulic Modelling. International Association for Hydraulic Research. German Association for Water Resources and Land Improvement, Stuttgart (1980)

4. D. Bousmar, HydroCap 3 Automatisation des measures sur modèle réduit hydraulique. Rapport de stage. Service public de Wallonie, Belgium (in French) (2008)

5. PIANC - The World Association for Waterborne Transport Infrastructure. Ship behaviour in locks and lock approaches. Report $\mathrm{n}^{\circ} 155$, Brussels, Belgium (2015)

6. Bousmar, D., Bertrand G., Hiver J.-M., Barlet S., Boogaard A., Elzein R., Veldman J.J. The approaches for the new class VIb lock at Ivoz-Ramet, River Meuse, Belgium. PIANC MMX Congress. Liverpool, UK (2010)

7. C. Swartenbroekx, D. Bousmar, Physical design of upper harbor at Auvelais lock, Belgium, submitted to 7th International Symposium on Hydraulic Structures, Aachen, Germany (2018) 